Kelly, A. 2015. 'Intimacy and emotional labour in academic development', International Journal for Academic Development vol 20, no 1, pp. 93-104 DOI:

10.1080/1360144X.2014.999075

\title{
Intimacy and emotional labour in Academic Development
}

Adrian Kelly, University of Technology, Sydney

Adrian.Kelly@uts.edu.au

Abstract

The affective dimensions of intimacy and emotional labour in academic development are explored utilising two methodological resources: autoethnography and narrative practice. An excerpt from the author's reflective professional journal infused with affect and emotion is analyzed utilizing theories of intimacy in modernity (Giddens 1990), emotion work (Hochschild 1983, 2012) and professional intimacy (Huebner 2007). The journal excerpt is 'restoried' (White and Epston 1990) to produce narrative lines that provide insight into the journal entry. The article concludes by proposing a 'pedagogy of intimacy' as an analytical space that values both skill and care.

Key words: academic development, affect, autoethnography, emotion work, intimacy, narrative therapy 


\section{Journal 20 May}

Monty was referred to me at the beginning of the semester because his student appraisals of teaching for the previous couple of semesters were very low. In my first meeting with Monty we went through his student feedback forms focussing particularly on the positive and negative messages students were giving him. I was conscious throughout the meeting to give Monty lots of positive reinforcement for the things he does well and for what the students liked about his teaching. This was not difficult, because the students wrote a lot of positive things. But there were some clear messages that the students were giving him: speak louder (can't hear you), speak clearer, and don't speak in such a monotone.

After summarising the student feedback, I discussed with Monty the strategies he could employ to address the negative issues identified by students. He told me that he was a retiring person: 'in a room full of people, I will be standing on my own by the wall' he explained. I suggested that there was a difference between a personality and a persona, and that perhaps by focussing on developing a teacherly persona as a type of act he put on when teaching, he might be able to find a different way to be in the classroom. I suggested he might observe one of his peers teaching a session, 'someone with a similar personality to you.' And perhaps he could explore toastmasters or something of that ilk to develop his ability to project his voice. I finished the meeting by reiterating the strengths of his work as a tutor. I told him about a situation in which my students had complained about my teaching and how difficult I found this. As I was bringing the meeting to a close, Monty began to cry. I wasn't sure how to respond to this and thought it best not to acknowledge it as I thought that might make it worse for him. Monty told me that he had been really worried about coming to see me and then he commented on how kind I had been to him. His tears were tears of relief. 
The memory of this encounter with Monty has stayed with me long after the events that are recounted. I am at once puzzled, troubled and also drawn to the memory of these events and it is these conflicting responses that have led me to want to explore this journal entry further. In this article I want to consider how we academic developers can think about this entry from my journal; what do artefacts such as this journal entry have to tell us about academic development work? My objective is to respond to what I perceive as a paucity of discourse regarding the affective dimensions of higher education by accounting for some of the ways in which 'the affective and embodied are already aspects of all pedagogical encounters' (Beard, Clegg \& Smith 2007, p. 236) including academic development encounters, in a discursive regime in which 'the role of emotions ... receives little or no attention in the contemporary popular texts of higher education, such as the work of Light and Cox (2001), Ramsden (2003) and Biggs (2003)' (Beard, Clegg \& Smith, p.237-8).

There are several steps that I need to take in order to take a reader on my journey of thinking about this journal entry. A very early step will be to set the encounter recounted in this journal entry into a meaningful context for the reader. Then to explore some literature that might help to illuminate the encounter. Finally to restory the encounter to open up discursive space for the insights gained into the encounter from this journey. However, before any of this, I think it will be important to place this journal entry and the research work done here into a methodological setting and to account for the way in which my experience is connected to "our" experience, the "we" who are academic developers (Grant 2007).

\section{Methodologies for capturing personal experience: autoethnography and narrative practice}

Like autobiography, autoethnography involves telling stories of the self. However, what distinguishes autoethnography from autobiography is that as a method it produces tales that are explicitly culturally situated and are used for reflexive meaning making; Haraway (1988) characterises this as 'situated knowledge'. Perhaps one of the most succinct, but by no means universally accepted, definitions of autoethnography is as 'an approach to research and writing that seeks to describe and systematically analyse (graphy) personal 
experience (auto) in order to understand cultural experience (ethno) (Ellis, Adams and Bochner 2011, p. 1).

The above journal entry, then, is the autoethnographic data for this research into my practice of academic development work in a particular higher education setting.

In contrast with objectivist and positivist approaches to research, autoethnography is written from the 'I Site' (Brodkey 1996) or in other words it takes the self as a site of inquiry. For Brodkey, this site has been dehistoricised by modernity in general and in academia in particular through the 'realist convention' (Haraway 1988) in academic writing, most particularly through avoidance of the use of first person pronouns.

For me, at least, historicising the spaces inhabited by the human body has meant a radical shift in ... how I imagine and study the multiple subjectivity of the self. In theoretical terms... the 'I' embodies relations between actually lived and socially produced spaces; in empirical terms, the 'I' is a site whose memories of lived experiences of social and historical spaces are recounted as narratives of personal experience; and in practical terms, everyone is an 'I Site' by definition and either already can or may well wish to explore in writing the historicised spaces of their personal narratives. (Brodkey 1996, p. 18)

Roth (2005, p. 15) argues that autoethnography is not about a retreat into the personal but is a means for establishing and stabilising intersubjectivity through the telling of credible stories. All of our knowledge is simultaneously embodied/singular and collective in that it represents a realisation of cultural-historical and sociocultural possibilities. We can distinguish

... two modes of cognitive function, two modes of thought, each providing distinctive ways of ordering experience, of constructing reality ... A good story and a well-formed argument are different ... kinds. Both can be used as means for convincing another. Yet what they convince of is fundamentally different: arguments convince one of their truth, stories of their lifelikeness. The one verifies by eventual appeal to procedures for establishing formal and empirical truth. The other establishes verisimilitude. (Bruner 1986, p. 11)

The autoethnographic work presented here will be combined with another methodology, Narrative Practice, to write into my journal entry to add my developing understanding of what I have recounted in the journal entry. While there is a broad array of methods and methodologies that sit within narrative frames, in this article I will be borrowing methods developed by Michael White and David Epston in the formulation of therapeutic techniques that are known as Narrative Therapy or Narrative Practice (White \& Epston 1990; 
White 1992). Key among these techniques will be 'restorying'; 'White and Epston found that persons tended to seek out therapy when the narratives they were telling (or somehow involved in) did not quite represent their lived experience and when there were vital aspects of their experience that contradicted dominant narratives about them' (Madigan 2011, p. 22). It is this aspect of Narrative Practice that has made it seem to me useful for working with my journal entry as my journal entry fails to represent my lived experience and memory of the events. So I will be deploying the therapeutic technique of restorying to non-therapeutic ends and I take encouragement in this in part from the insight that Narrative Practice has been characterised as a 'counter-therapy' (Besley 2001, p. 78), that there is a well-trodden migratory path of ideas from therapy to education, a significant example being Rogerian educational theory and methods, and also that the psychotherapeutic relationship can be seen as a particular type of pedagogic relationship. Within my journal narrative I will be seeking 'lines of flight' - a notion drawn from Deleuze and Guattari (1987) - as narrative lines that resist the restraints of dominant discourses or codes of power (molar lines) and present opportunities for restorying persons, situations and events. For restraints, or lines of force, 'always produce lines of resistance, and power relations are given shape as much by the lines of resistance as by the lines of force' (Avalos \& Winslade 2010, p. 76). Narrative practice then is about finding and constructing the territorial shifts that are made possible by following lines of flight (Avalos \& Winslade 2010, p. 77) in order to restory and therefore discursively reconstruct selves and experience.

\section{Contextualising relations}

The events represented in my journal entry are framed by a range of 'contextualising relations' (Lemke 1995, p. 167) and my representation of participants in the encounter is positioned by those contextualising relations and broader discursive forces. Lemke explains that,

Meaning consists in relations and systems of relations of relations. These relations are basically contextualizing relations; they tell us what the contexts are in relation to which an act or event has its meanings ... (p. 167, italics in original) 
The 'I Site' of my journal entry is when I was working as the Academic Manager in an Australian non-self-accrediting higher education institute (NSAI) which I will henceforth refer to as the 'Institute'. As Academic Manager I was responsible for the academic development of about 100 sessional lecturers and tutors who taught into Diploma courses that were made up of the first year subjects of undergraduate degrees in an affiliate Australian public university. The university made the subject content and documents available to the Institute but the subjects were delivered in significantly different ways at the Institute: more tutorial hours, smaller classes, and more scaffolded assessment. As Academic Manager I was an ex officio member of the Academic Board. Statistical data developed from student responses to Student Evaluation of Teachers surveys and Student Evaluation of Subjects surveys were presented to the Academic Board as part of the quality assurance mechanisms of the Institute and the Board recommended interventions to improve the Institute's performance in the surveys. Key in the Board's arsenal for improving these performance indicators were professional development workshops and academic development 'counselling'/mentoring for individual 'underperformers'. As such, this constitutes a higher level of observation and monitoring of individuals than may be the case in other Australian higher education institutions. These then are the key 'contextualising relations' that frame the meaning potential for the encounter presented in my journal entry. Monty has come to me to be counselled and/or mentored in order to modify his performance in the eyes of his students and therefore the Institute's survey results.

\section{Illuminating the encounter}

What strikes me when reading my journal entry are the multiple levels of intimacy related to this text. There are the levels of intimacy involved in the experiential content of the text, an academic coming to see me to engage in the dissection of his learners' evaluations of his teaching. Additionally there are the levels of intimacy that ensue in my reflection and then later, my reflection upon my reflection. My concern when writing the journal entry was with my practice; I was engaged with the questions 'have I done the right thing?' 
'Have I approached this appropriately/skillfully/professionally?' There is also a level of intimacy here, in which the professional acts behind closed doors and the 'client' subjects her/himself to the processes, procedures, investigations and ministrations of the professional - Foucault (1978, p. 59; Taylor 2009) characterizes this as the 'confessional apparatus'.

It interests me that my reflection written close to the meeting with Monty focused on particular aspects of my practice, while, without the aid of this reflective journal excerpt, my strongest memory of my meeting with Monty was the fact that he cried and I can still vividly recall the feelings that passed through my body as I considered how I could respond to his tears. Time seemed to slow and I remember sitting very still, but I remember my thoughts racing as I wondered how I might best respond. I felt at once vulnerable and perhaps a bit frightened, and simultaneously aware of my power in that my actions had potential for significant impact upon Monty. I felt unprepared, ill-equipped and ... unpremeditated; but acutely aware of the importance of my responses. At the time I chose to not respond ... but of course it is impossible not to respond, so perhaps it would be clearer to say that my responses only very obliquely acknowledged that he was crying. I was conscious of minimising his emotional disassembly. I also remember this moment with great affection for it was a very tender moment between two people who hardly knew each other and who have had very limited contact since. That moment was intimate and I was aware that how I chose to act was of ethical and professional significance. While there was a degree of discomfort for me, this originated not in my aversion to his tears but in my uncertainty about how I might respond. I started to look for literature pertaining to 'intimacy' and was not surprised when most of what turned up was about sexual intimacy. However, I did locate a few pieces of literature (Giddens 1990; Hochschild 1979; Huebner 2007) that dealt with intimacy more generally or in professional settings and I wondered if these would help illuminate the encounter recounted in my journal entry. 


\section{The transformation of intimacy}

Giddens (1990) explores how the abstract systems of modernity have transformed intimacy. Modernity's abstract systems, such as our food production, transportation systems and provision of facilities to our homes, make social life possible in large arenas of secure, coordinated actions and events. As globalisation has accelerated, the connections between our personal lives and disembedding systems have intensified: a prime example of this is the globalised system of food production - 'Every cup of coffee contains within it the entire history of Western imperialism' (Giddens 1990, p. 120). At the same time new forms of psychological vulnerability result because trust in abstract systems is not as psychologically rewarding as trust in persons. For Giddens (1990, p. 114), 'personal trust relations, in such circumstances, are closely bound up with a situation in which the construction of the self becomes a reflexive project.'

Giddens observes that friendship has seldom been studied by sociologists but is a key aspect of the organisation of personal life and a site of intimacy both in pre-modern and modern times.

\footnotetext{
No doubt companionships sustained through emotional warmth and purely personal loyalty have existed in all cultures. But in the pre-modern world friendships were always liable to be placed in the service of risky endeavours where community or kinship ties were insufficient to provide the necessary resources - in forging economic connections, avenging wrongdoings, engaging in wars, and in many other activities... Codes of honour were in effect public guarantees of sincerity, even where the "goods" the friendship relation was called upon to deliver placed it under great strain. (Giddens 1990, p. 118-9)
}

In this pre-modern context the opposite of 'friend' is 'enemy'. Friendship is transformed in the vast extension of abstract systems of modernity. Loyalty replaces honour, relying not on codes but on personal affection and authenticity wherein the other is required to be open and well-meaning. No longer is friend contrasted with enemy, but now in relation to acquaintance, colleague or someone I don't know. Social existence, then, comes to rely on trust: trust in impersonal principles and anonymous others. 
Trust on a personal level becomes a project, to be "worked at" by the parties involved, and demands the opening out of the individual to the other. Where it cannot be controlled by fixed normative codes, trust has to be won, and the means of doing this is demonstrable warmth and openness. Our peculiar concern with "relationships," in the sense which that word has now taken on, is expressive of this phenomenon.

Relationships are ties based upon trust, where trust is not pre-given but worked upon, and where the work involved means a mutual process of self-disclosure. (Giddens 1990, p. 121, italics in original)

Using Giddens's analysis of modern forms of intimacy, Monty and I can be regarded as engaging in the process of relationship building, albeit a relationship of limited duration. Our relationship is not governed by a public code of honour that would have existed in a pre-modern friendship, but within the context of a collegial encounter, albeit stratified, which nevertheless relies upon the building of trust through the process of working on 'the opening out of the individual to the other' (Giddens 1990, p. 121). For this reason at times during the encounter I actively 'worked on' minimising the social distance between Monty and myself through disclosure of my own vulnerabilities as a teacher. At other times, the social distance was utilised to establish the 'adviser' voice who endorsed the positive feedback that students provided, focused the student feedback on specific features of Monty's teaching performance that I wanted to address, and provided specific advice about what to do about these: select a fellow lecturer or tutor who has a similar personality type to you, observe that person teaching. The journal entry also exhibits the sort of reflexive project that Giddens regards as necessary to a society organised around abstract systems. So my reflections upon my encounter with Monty centre on my concerns about who I was being and how I was enacting my subjectivity in relation to Monty and the institutional and experiential context of the encounter.

Giddens (1990, p.121) remarks that trust can only be won through 'demonstrable warmth and openness' and this points to the reasons Monty's tears constituted such a critical point in the encounter. My reactions could have resulted in either severance or a modern form of intimacy, but I couldn't find the discursive resources to demonstrate this. Was warmth and openness communicated? I will never know, but I suspect not; yet Monty tells me that his tears emanate from his relief that I have been 'kind' and presumably 
also that he is not going to be humiliated or lose his job. When Monty's emotions 'intruded' into this space, my concerns to minimize the impact of that 'intrusion' were ethical endeavours to establish a field of imminent power in which I continued to operate effectively as an academic developer.

Bringing together Giddens's analysis of the transformation of intimacy in modernity and academic development as bedfellows in this analysis illuminates the way in which the intimate dimensions of our work so easily slip from view. While Giddens and academic development may not appear to be natural bedfellows, we can see that relational capacities such as developing empathy, self-disclosure, minimising distance and communicating warmth can have critical impact on the unfolding of an academic development encounter.

Having explored with Giddens how intimacy has been transformed in modernity, I want to move now to the emergence of new forms of intimacy in the abstract systems of modernity and their framing as emotion work and professional intimacy.

\section{Emotion work and professional intimacy}

Hochschild (1979, p. 561) would characterise the events described in this journal excerpt as 'emotion work,' which she defines as 'the act of trying to change in degree or quality an emotion or feeling.' She equates 'working on' an emotion with 'managing' an emotion or doing 'deep acting'.

An actor playing the part of King Lear might go about his task in two ways. One actor, following the English school of acting, might focus on outward demeanor, the constellation of minute expressions that correspond to Lear's sense of fear and impotent outrage ... Another actor, adhering to the American or Stanislavsky school of acting, might guide his memories and feelings in such a way as to elicit the corresponding expressions. The first technique we might call "surface acting," the second "deep acting." (Hochschild 1979, p. 558)

Emotion work refers to the attempt to regulate affect towards ideal formulations whether such an attempt is successful or not. This notion of emotion work sits within an interactive account of emotion that 
constructs emotion as normative interaction between psychological factors and sociological notions of appropriateness. The interactive account stands in contrast with an organismic view of emotion as

a sudden automatic reflex syndrome - Darwin's instant snarl expression, Freud's tension discharge at a given breaking point of tension overload, James and Lange's notion of an instantaneous unmediated visceral reaction to a perceived stimulus, the perception of which is also unmediated by social influences. (Hochschild, 1979 p. 553-4)

Hochschild distinguishes emotion work from emotion control or emotion suppression but (somewhat confusingly because she then goes on to use the term suppression) divides emotion work into two:

evocation, in which the cognitive focus is on a desired feeling which is initially absent, and suppression, in which the cognitive focus is on an undesired feeling which is initially present.(1979, p. 561)

One can do emotion work on oneself, or solicit assistance so that emotion work is done by others upon us, and therefore we can also do emotion work on others. Hochschild explains that emotion work can be cognitive, or the attempt to change emotions by changing thoughts, ideas or images, bodily, or the attempt to alter somatic emanations of emotion through such techniques as breath control or resistance to shaking, and expressive, such as smiling or attempting to cry as techniques for altering feeling.

Using Hochschild's notion of emotion work, I might view myself as being engaged in 'trying to change in degree or quality [my] emotion or feeling' $(179$, p. 561). Both 'surface' and 'deep' dimensions are present. 'Surface' dimensions include the locating of the encounter in a private room behind a closed door, sitting at a table together (rather than sitting behind a desk), eye-contact, soft tone of voice, attentive listening - many of these 'mundane' dimensions were not recorded in the journal entry as such 'minutiae' seemed at the time beyond interest. Yet these details are essential to the affective flow of the encounter. 'Deep' dimensions are more explicitly present in the journal: my attempts to focus on positive aspects and to view Monty in a positive light; my empathetic attempts to identify with his challenges by suggesting a 'persona' 
rather than a personality; revelations of my own vulnerabilities as a teacher. In Hochschild's terms, these 'deep' dimensions function as evocations used to communicate emotion that might otherwise seem to be absent, and these evocations are cognitive, bodily and expressive.

Some years after the events captured in this journal entry I was working with a graduate Nursing student on some research she was conducting and one of the theoretical concepts she was working with was 'professional intimacy'. Since that time, Monty's crying has become emblematic for me of this notion of professional intimacy in relation to academic development work. I wondered what scholarly and practiceoriented explorations I might find in relation to this notion of professional intimacy and what insights they might have to the theory and practice of academic development.

\section{Economies of intimacy: feminisation, dichotomisation and invisibility}

Huebner's (2007) doctoral thesis 'names and analyzes professionally intimate labor' in the context of nursing which she admits may seem 'a strange analytic combination' (p.1). Huebner identifies the false dichotomy of private acts of intimacy and paid public acts as the mechanism by which professional intimacy is kept invisible and asserts that in both the family and in employment intimacy is motivated by both love and money (p.2). This invisibility belies the skill, experience and strategy that are inherent in the capacity for professional intimacy. 'Revealing the meaning and practices of professional intimacy ... thus challenges the neoliberal ideas of individualism by emphasizing interdependency and mutual need in professional work' (Huebner, 2007, p. 3). This can be characterised as tacit knowledge, and as such practitioners themselves may not be able to articulate how the knowledge and skills are developed or analyse what the skills are. In Huebner's study, nurses often characterised professional intimacy as personal characteristics rather than labour activities (p. 7). Along with this, according to Huebner, neoliberal 'economies of intimacy' ignore human desire and need to give and receive care. 'The concept of professional intimacy provides an analytical space to value care and interdependency’ (p. 13). 
The context of Huebner's study, nursing, is quite different from academic development work but for me this shift of context provides some interesting parallels. The intimacy of academic development encounters is not prominent in academic development theoretical literature and perhaps is viewed dichotomously with skill in much the same way as the discourse of nursing dichotomises intimacy and skill:

Nursing straddles a dichotomy: it is seen as either nurturing or rational. When discussed as nurturing, nursing is viewed as based on natural traits inherent in certain individuals. When discussed as rational, nursing is regarded as a set of medical or technical skills that can be taught. This false duality - virtue or skill - precludes an assessment of how these function simultaneously in nursing since professional intimacy requires both skill and caring. (Huebner 2007, p.5)

\section{Restorying intimacy}

Through this 'lens' of professional intimacy, I read my academic development meeting with Monty as an intimate encounter that calls upon professional skill and caring. I do not read these as a set of natural traits inherent in certain individuals but a set of professional skills that need to be developed. The following restorying of this journal entry, will attempt to identify the operations of neoliberal 'economies of intimacy' (Huebner 2007, p. 13) in the encounter and resist the characterisation of this intimate dimension as simply personal characteristics of the participants. The use of italics will mark these restoried elements. The intimate dimension will be recast as interdependency and mutual need in which the intimate dimensions flow in relation to professional levels of experience, strategy and skill.

\section{Restoried Journal 20080520}

Monty was referred to me at the beginning of the semester because his student appraisals of teaching for the previous couple of semesters were very low. In my first meeting with Monty we went through the student feedback forms focussing particularly on the positive and negative messages students 
were giving him. I was conscious throughout the meeting to give Monty lots of positive

reinforcement for the things he does well and the students like about his teaching - this consciousness was a strategic move in which I sought a desensitisation of the intimate dimensions of student feedback on teaching and the establishment of trust and mutual respect. This was not difficult, because the students wrote a lot of positive things. But there were some clear messages that the students were giving him: speak louder (can't hear you), speak clearer, and don't speak in such a monotone. At this point, naming the criticisms operates to further desensitise and allows the relative importance or weight of the criticisms to be evaluated. By contrast, leaving the criticisms unnamed enables them to become inflated by fear.

After summarising the student feedback, I discussed with Monty the strategies he could employ to address the negative issues identified by students. He told me that he was a retiring person: 'in a room full of people, I will be standing on my own by the wall' was how he described himself. Monty's self-disclosing comments here signal that he has contributed to the flow of intimacy in this encounter. He may have felt coerced into this disclosure by the context of the meeting; to minimise this sense, I maintained an emphasis on the privacy and safety of this intimate space that he has disclosed in. I suggested that there was a difference between a personality and a persona, and that perhaps by focussing on developing a teacherly persona as a type of act he put on when teaching, he might be able to find a different way to be in the classroom. I suggested he might observe one of his peers teaching a session, 'someone with a similar personality to you.' And perhaps he could explore toastmasters or something of that ilk to develop his ability to project. I wonder whether such suggestions are particularly effective. I suspect that what is more powerful about this context is that once the issues have been identified and exist in intimate discourse between us, it is Monty's formulations of what might be the next steps that are more likely to lead to changes in his practice. I 
finished the meeting by reiterating the strengths of his work as a tutor. I told him about a situation in which my students had complained about my teaching and how difficult I found this. As I was bringing the meeting to a close, Monty began to cry. I wasn't sure how to respond to this and thought it best not to acknowledge it as I thought that might make it worse for him. Monty told me that he had been really worried about coming to see me and then he commented on how kind I had been to him. His tears were tears of relief. My uncertainty in how I might respond to Monty's tears points to a heightened awareness of interdependency between Monty and me in this meeting: I need the meeting to be rewarding and an opportunity for me to do my work well as much as Monty needs to feel safe and to be treated with respect. My uncertainty is perhaps symptomatic of my awareness that experience, strategy and skill need to be applied to this situation in order that the meeting proceeds to a satisfactory conclusion for both of us. This also points to an economy of intimacy wherein tears in a professional encounter between men can be seen to introduce into the economy of the encounter 'currency' that is not recognised or valued and in fact is explicitly externalised. A dominant narrative in which tears and emotional disassemblage do not accrue value is disrupted by the intrusion of tears and a subjugated alternative narrative starts to be formed.

In this restoried journal I am engaged in a particularly modern form of relationship building. The setting is an office and the relationship is construed as collegial rather than friendship, and stratified into roles of academic developer and sessional academic. Intimacy is constructed through self-disclosure and this ebbs and flows between participants. This self-disclosure is tactical, at least on my part, and forms strategic alliance-building functions in the encounter. Intruding into this modern setting are tears and emotional disassemblage that become the most tangible aspects of the emotion work that both Monty and I are engaged in. This is not in Hochschild's $(1979 ; 1983,2012)$ sense of 'emotion work' as pretending something that has no essential reality to a 'true' self and thereby dichotomising skill and caring, but rather in Huebner's (2007) 
sense of demonstrating a capacity for professional intimacy which operates as an analytical space for valuing both caring and skill. Whilst at times I have been critical of how I engaged with Monty at this time, through the process of restorying and researching intimacy as a theoretical space, I have come to see myself as operating intently to work within an emotionally charged space to accommodate the emotional and the intimate within this professional context.

\section{Conclusion}

In this article, I have investigated what I experience as intimate dimensions to my academic development work. My reading of literature pertaining to intimacy in modernity, emotion work and professional intimacy has led me to consider intimacy as discursively formed and in modernity predominantly conceived of as self-disclosure. By writing into my journal and restorying the encounter I can start to identify the dynamic flows of intimacy in this encounter. For me this becomes a pedagogic space in which Monty and I are learning from each other how to conduct ourselves in a professionally intimate manner. This then is a 'pedagogy of intimacy', that is, a pedagogic space in which disclosure is exchanged for externalisation and restorying and in which the capacity for professional intimacy is conceived as a combination of both skill and care. By viewing this encounter as an instantiation of cultural-historical and sociocultural possibilities pertinent to academic development work, I propose that professionally intimate capacities and skills communicate this care: developing empathy, self-disclosure, minimising distance, communicating warmth inter alia have been illuminated by this restorying process. These insights may make explicit some of the dynamics in place in academic development encounters and prove useful in redirecting encounters when intimate dimensions become troubling for academic developers.

\section{Biography}


Adrian Kelly is Senior Lecturer, Learning Development at Jumbunna Indigenous House of Learning, University of Technology, Sydney. Adrian has worked as an academic developer since 2004 and his work has primarily been focussed on working with lecturers and tutors teaching into the first year of undergraduate degrees. Adrian also designs, develops and oversees the delivery of learning assistance schemes for students in access programs. He currently coordinates and provides academic development opportunities to a team of over forty casual academics who provide supplementary tuition to Indigenous students at the University of Technology, Sydney.

\section{References}

Avalos, M. \& Winslade, J. (2010). Education as a 'line of flight'. Explorations: An E-Journal of Narrative Practice 1, 70-7. Retrieved from http://www.dulwichcentre.com.au/explorations-2010-1-marielavalos-john-winslade.pdf

Beard, C., Cleg, S. \& Smith, K. (2007). Acknowledging the affective in higher education, British Educational Research Journal 33(2), 235-252.

Bruner, J. (1986). Actual minds, possible worlds. Cambridge, Massachusetts: Harvard University Press.

Deleuze, G \& Guattari, F. (1987a). A thousand plateaus. Capitalism and schizophrenia. Minneapolis: University of Minnesota Press.

Deleuze, G \& Guattari, F. (1987b). A thousand plateaus. Capitalism and schizophrenia. London: Continuum. Ellis, C., Adams, T. E. \& Bochner, P. (2011). Autoethnography: An overview. Forum Qualitative Sozialforschung / Forum: Qualitative Social Research 12(1), art. 10.

Foucault, M. (1978). The history of sexuality. Volume 1. An introduction, London: Penguin.

Giddens, A. (1990). The consequences of modernity. California: Stanford University Press.

Grant, B. (2007). The Mourning After: Academic development in a time of doubt. International Journal for Academic Development 12(1), 35-43.

Haraway, D. 1988, Situated knowledges: the science question in feminism and the privilege of the partial perspective, Feminist Studies vol. 14, no. 3, pp. 575-99. 
Hochschild, A. R. (1979). Emotion work, feeling rules and social structure. American Journal of Sociology $85(3), 551-75$.

Hochschild, A. R. (1983, 2012). The managed heart: the commercialization of human feeling. Berkeley: University of California Press.

Huebner, L. C. (2007). Professional intimacy: an ethnography of care in hospital nursing. PhD thesis, Pennsylvania: University of Pittsburgh.

Madigan, S. (2011). Narrative Therapy, Washington, DC: American Psychological Association.

Roth, W. M. (ed) (2005). Auto/biography and auto/ethnography: praxis of research method. Rotterdam: Sense Publishers.

Taylor, C. (2009). The culture of confession from Augustine to Foucault. A genealogy of the 'confessing animal'. New York: Routledge.

White, M \& Epston, D. (1990). Narrative means to therapeutic ends. New York: W. W. Norton \& Company.

White, M. (1992). Deconstruction and Therapy. In D. Epston and M. White (Eds.), Experience, contradiction, narrative \& imagination: Selected papers of David Epston \& Michael White 1989-1991, (pp. 109-151) South Australia: Dulwich Centre Publications. 